\title{
Impact of high-resolution data assimilation of GPS zenith delay on Mediterranean heavy rainfall forecasting
}

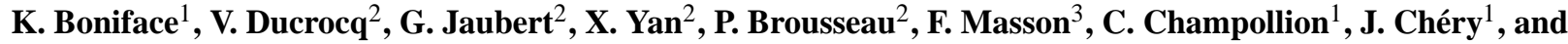 \\ E. Doerflinger ${ }^{1}$ \\ ${ }^{1}$ Géosciences Montpellier, UMR 5243 CNRS-UM2, CC. 60, Place E. Bataillon, 34095 Montpellier Cedex 5, France \\ ${ }^{2}$ GAME-CNRM, CNRS-Météo-France, 42 Avenue Coriolis, 31057 Toulouse Cedex 1, France \\ ${ }^{3}$ UMR 7516-IPGS-CNRS-EOST, 5 rue René Descartes, 67084 Strasbourg Cedex, France
}

Received: 20 March 2009 - Revised: 24 June 2009 - Accepted: 1 July 2009 - Published: 9 July 2009

\begin{abstract}
Impact of GPS (Global Positioning System) data assimilation is assessed here using a high-resolution numerical weather prediction system at $2.5 \mathrm{~km}$ horizontal resolution. The Zenithal Tropospheric Delay (ZTD) GPS data from mesoscale networks are assimilated with the 3DVAR AROME data assimilation scheme. Data from more than 280 stations over the model domain have been assimilated during 15-day long assimilation cycles prior each of the two studied events. The results of these assimilation cycles show that the assimilation of GPS ZTD with the AROME system performs well in producing analyses closer to the ZTD observations in average.

Then the impacts of assimilating GPS data on the precipitation forecast have been evaluated. For the first case, only the AROME runs starting a few hours prior the triggering of the convective system are able to simulate the convective precipitation. The assimilation of GPS ZTD observations improves the simulation of the spatial extent of the precipitation, but slightly underestimates the heaviest precipitation in that case compared with the experiment without GPS. The accuracy of the precipitation forecast for the second case is much better. The analyses from the control assimilation cycle provide already a good description of the atmosphere state that cannot be further improved by the assimilation of GPS observations. Only for the latest day (22 November 2007), significant differences have been found between the two parallel cycles. In that case, the assimilation of GPS ZTD allows to improve the first 6 to $12 \mathrm{~h}$ of the precipitation forecast.
\end{abstract}

Keywords. Meteorology and atmospheric dynamics (Mesoscale meteorology; Precipitation) - Radio science (Remote sensing)

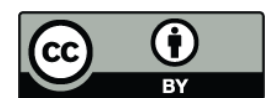

Correspondence to: $\mathrm{K}$. Boniface (karen.boniface@gm.univ-montp2.fr)

\section{Introduction}

Humidity is recognized as the least well analyzed parameter in the current operational assimilation systems, partly because of this parameter is highly variable in space and time. Thus, mesoscale distribution of moisture is in general not well monitored. The rapid development of ground-based GPS networks in the past years supplies a new source of such mesoscale humidity information. Because water vapour modifies atmospheric refractivity, satellite-receiver path delays provide a unique information on the total integrated water vapour (IWV) within the troposphere (see Bevis et al., 1992).

Indeed the Zenith Total Delay (ZTD) obtained from GPS data processing represents the vertically integrated refractivity which is function of pressure, temperature and particularly water vapour mixing ratio in the column above the receiver (Saastamoinen, 1972).

Since a decade, GPS (Global Positioning System) technique has shown the ability to estimate the vertically Integrated Water Vapour (IWV) (e.g. Bevis et al., 1992; Champollion et al., 2004), with an accuracy of about $1 \mathrm{~kg} \mathrm{~m}^{-2}$ comparable to standard errors associated with other water vapour measuring instruments. The comparison with independent observing techniques such as Radiosounding (RS) and microwave radiometers yields to an agreement on the level of $1-2 \mathrm{~kg} \mathrm{~m}^{-2}$ RMS (Root Mean Square) (see among others, Bock et al., 2005; Rocken et al., 1995; Emardson et al., 1998; Kopken, 2001; Klein Baltink et al., 2002). Several studies have shown the interest to exploit the GPS observations in Numerical Weather Prediction (NWP) systems either for validation of the model forecasts or for improving the model initial conditions (Zou et al., 1995; Kuo et al., 1996, 1998; Vedel and Huang, 2004; Zhang et al., 2008). Most of the studies showed that the impact of assimilating GPS data is generally neutral, but positive for strong precipitation. The potential of GPS data assimilation for improving

Published by Copernicus Publications on behalf of the European Geosciences Union. 
forecast of heavy precipitation that often occurred in Northwestern Mediterranean during fall had thus been further studied. Vedel et al. (2004) found that GPS data assimilation improved the forecast of a severe Mediterranean rain event and concluded that GPS data had good potential for improving NWP forecasts in rapidly developing high-moisture flow situations that characterized the heavy rainfall events occurred over the French and Spanish Mediterranean regions. To date, ground-based GPS dense networks are unique to provide vertically integrated tropospheric water vapour observations at spatial and temporal resolutions that cope with the mesoscale extend and variability of such moist plumes. Indeed radiosonde stations are few and far between for adequately resolve temporal and spatial scales and also because of a limited number of launches and device cost (Anthes, 1983).

Former studies had examined the impact of assimilating GPS observations on the quantitative precipitation forecast produced by large scale or mesoscale models using deep convection parametrization. However, it is known that convection-resolved and convection-parametrized models can provide different forecasts starting from the same initial conditions (Ducrocq et al., 2002). Recently, Yan et al. (2008) assessed thus the impact of GPS improved initial conditions using a high-resolution convection-resolved model. They found a slight positive impact on the convectivescale $(2.5-\mathrm{km})$ forecast of a heavy precipitation episode over Southeastern France. The assimilation of GPS data was however performed with the 3D-VAR data assimilation system at $9.5 \mathrm{~km}$ resolution. The present study goes one step further in performing both the data assimilation cycle and the subsequent model forecast at $2.5-\mathrm{km}$ resolution. Performing the assimilation at such high resolution should help the assimilation processes by providing better model equivalent ZTD due to better first-guess and more accurate model terrain. Also, to better describe the moist mesoscale low-level flow that feeds up the Mediterranean heavy precipitation systems, our study makes use of data from a regional GPS network over Southeastern France in addition to those from the operational European E-GVAP (The EUMETNET (Network of European Meteorological services) GPS Water Vapour Program) network.

Various methods exist to quantify the impact of the assimilation of a specific observing system in numerical weather prediction (NWP) systems. A classical way is to perform Observing System Experiments (OSE), which consists in excluding one particular data set over a long assimilation period and compare the skill of the analysis and forecast with respect to a parallel experiment, which assimilates all the available observations. This method has been applied here by performing two parallel data assimilation experiments with and without GPS ZTD assimilation for two 15-day long periods. At the end of each assimilation period, the impact of assimilating GPS ZTD is assessed for the two heavy precipitation events occurred over Southeastern France during autumn 2007.
The outline of this paper is as follows. The NWP convective-scale system used in the study is presented in Sect. 2. The assimilated GPS ZTD observations are described in Sect. 3. Section 4 details the OSE applied to the two precipitation events. Results of these experiments are discussed in Sect. 5. Conclusions are presented in the final section.

\section{NWP system description}

\subsection{Convective-scale analysis and forecast system}

In this work, we use the new operational fine-scale AROME NWP system from Météo-France (Bouttier, 2007). AROME is run at $2.5-\mathrm{km}$ horizontal resolution over a domain covering mainly France (Fig. 1). AROME is a non-hydrostatic model, based on an extension of the adiabatic equations of the limited-area NWP model ALADIN (Bubnova et al., 1995; Benard, 2004). The AROME physical parametrizations are selected among the physical package of the Meso-NH research model (Lafore et al., 1998). These include a bulk microphysical scheme (Caniaux et al., 1994) that governs the prognostic equations of the six water species (vapour, cloud water, rain water, primary ice, graupel and snow). No deep convection parametrization is used, as deep convection is resolved explicitly for the $2.5 \mathrm{~km}$ grid. The turbulence scheme is from Cuxart et al. (2000) and the radiative RRTM (Rapid Radiative Transfer Model) parametrization is used (Mlawer et al., 1998). The surface energy exchanges are represented according to the four possible surface type patches (nature surfaces, urban areas, ocean, lake) included in a grid mesh. The Interactions Soil-Biosphere-Atmosphere (ISBA) scheme (Noilhan and Mahfouf, 1996) is used for natural land surfaces, whereas energy exchanges over urban surfaces are parametrized according to the Town Energy Balance (TEB) model (Masson, 2000).

The AROME data assimilation scheme is for a large part common with the ALADIN and ARPEGE NWP systems from Mété-France and the IFS system from ECMWF. The 3DVAR/AROME scheme is quite similar to the 3DVAR/ALADIN system (Fischer et al., 2005; Montmerle et al., 2007), in terms of incremental formulation (Courtier et al., 1994), observation operators, minimization method and data flow. The background error covariances are however adapted to the higher resolution, estimated by an ensemble-based method (Berre et al., 2006), with a six member ensemble of AROME forecasts carried out over two 15-day periods. The two components of the wind, temperature, specific humidity and surface pressure are analyzed on the $2.5-\mathrm{km}$ grid while the other model fields (e.g. microphysical variables) are cycled from the previous AROME guess. A Rapid Update Cycle (RUC) is performed with 3-h forecast/analysis steps each $3 \mathrm{~h}$ (Fig. 2). From the 00:00, 06:00, 12:00 and 18:00 UTC AROME analyses, 30-h 


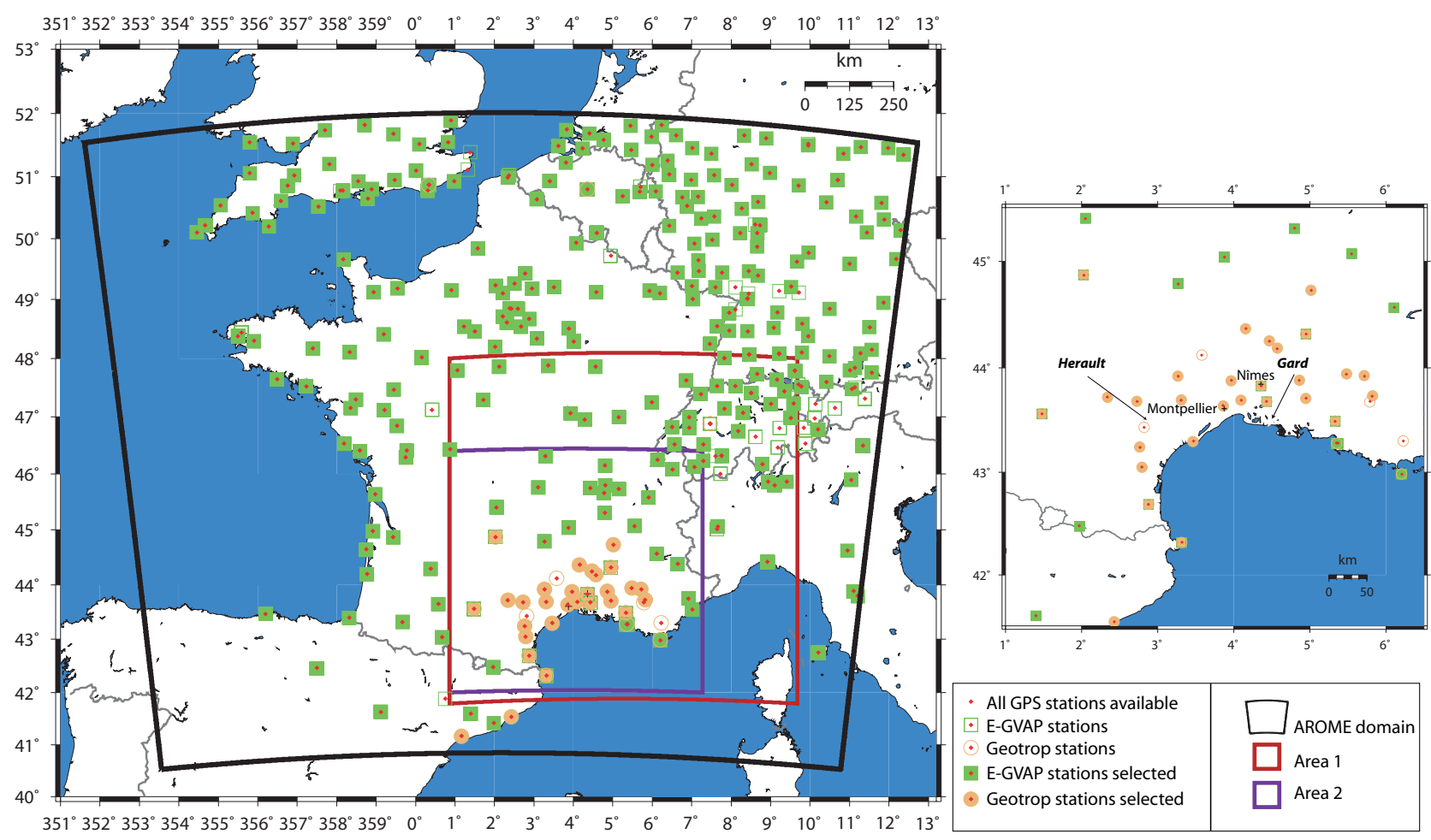

Fig. 1. GPS stations NRT processed by E-GVAP and post-processed for Geotrop network over the Arome domain for the selection period in fall 2007. On the right side, zoom of the area of interest with geographical names.

AROME forecasts are issued operationally each day using the ALADIN-France forecasts as lateral boundary conditions.

\subsection{ZTD observation operator}

To compute the innovation vector (observation minus firstguess) of the variational cost function, a model equivalent ZTD needs to be estimated at each location of the observations using the 3-h AROME forecast. The principle of the GPS ZTD observation operator consists in the integration of the index of refractivity over the model column above the GPS receiver. The refractivity index is a function of the total pressure $P$, the temperature $T$ and the partial pressure water vapour $e$. The observation operator used in this study, which is the same as the one used in the ARPEGE system (Poli et al., 2007), is based on the following expression:

$\mathrm{ZTD}_{\mathrm{MODEL}}=\int_{z_{g}}^{\mathrm{TOM}}\left(k_{1} \frac{P}{T}+k_{3} \frac{e}{T^{2}}\right) d z$

with $k_{1}=77.6 \mathrm{~K} \mathrm{hPa}^{-1}, k_{3}=3.73910^{5} \mathrm{~K}^{2} \mathrm{hPa}^{-1}$, according to Smith and Weintraub (1953). $z_{g}$ is the altitude of the ground-based receiver and TOM the altitude of the model top, currently at $1 \mathrm{hPa}$ for AROME. When the station is located below the model bottom, ZTD contribution is computed using extrapolated temperature, pressure and specific

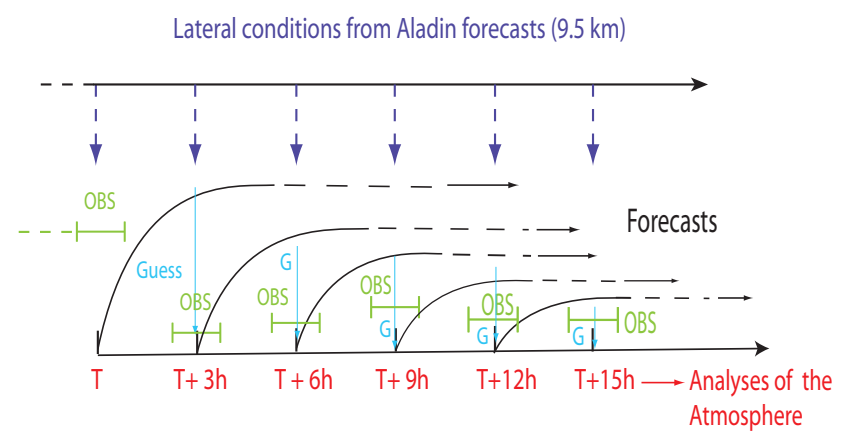

Fig. 2. Principle of the AROME 3D-Var rapid update cycle data assimilation.

humidity assuming the hydrostatic relationship and constant specific humidity and temperature down to the station height. This observation operator neglects the contribution of the atmosphere located above the model, which is estimated to about $2.3 \mathrm{~mm}$ for the AROME domain. The bias correction described in the following section is able to remove this constant error. The reader is refered to Poli et al. (2007) for a more comprehensive description of the observation operator. 


\section{GPS ZTD observations}

\subsection{GPS networks}

\subsubsection{The E-GVAP network}

Our data assimilation experiments use two kinds of GPS ZTD data sets. The first data set gathers GPS ZTD from several European GPS stations networks. The GPS ZTD issued from the different networks are collected and transmitted to the European NWP centers in near-real time (NRT) thanks to E-GVAP (http://egvap.dmi.dk/). The data processing to produce ZTD is not performed by a unique center, but by about ten centers. Several different solutions for a same GPS ground-based station can therefore be available, since each solution depends on the type of data processing used by each data centre. Data from more than 400 stations are available all over Europe processed in near-real time by 11 GPS data processing centres. The sampling rate is between 5 and 60 min depending on the data processing centre strategy.

\subsubsection{The Geotrop network}

The second source of data used comes from a regional permanent network located in South of France called Geotrop (http://www.gm.univ-montp2.fr/geotrop/). Geotrop gathers data from GPS stations hosted by public institutes deployed within the OHM-CV (Observatoire Hydrométéorologique Méditerranéen Cévennes-Vivarais), other stations are hosted by the RGP network (Réseau GPS Permanent) or RENAG (REseau NAtional GPS). The network is also composed of fifteen stations from the ORPHEON private company. These different data sources allow to reach a spatial resolution of about $50 \mathrm{~km}$ in the area of interest in South of France. The stations used in these studies are marked by red dots in Fig. 1, those from the E-GVAP network are marked by green squares, and by orange-circled for those from the Geotrop network.

All stations contained in the Geotrop regional network are processed by Géosciences Montpellier with a dedicated data processing. Raw GPS observations have been processed to issue 30 min accurate GPS ZTD with the GAMIT software release 10.32 (see King and Bock, 2007). Data processing is performed fifteen days after data acquisition which allows to use precise orbits, while the data issued by the affiliated EGVAP centres are computed in Near Real Time (NRT) with less precise orbits positioning. During a first run, GPS stations coordinates are estimated. This run is applied using ten GPS stations from Western Europe as a reference. This allows to have an optimal number of a priori constraints and so a precise ZTD estimation (see Tregoning et al., 1998). These are re-used for a second run that delivers atmospheric parameters: ZTD and horizontal gradients (not used here). The mapping function selected for mapping down the total delays is the Global Mapping Function (GMF) (see Niell,
1996). We use 24-h session to process the delays. To minimize edge effects of the processing only the central 12-h of the session are kept because the Gamit inversion computation is less accurate for the boundary hours session. Thus the processing need to be realized with 24-h session with 12 $\mathrm{h}$ overlapping sessions (for more details, see Champollion et al., 2004; Brenot et al., 2006, among others).

\subsection{Data GPS pre-processing}

Pre-processing of GPS ZTD data prior their assimilation by the 3DVAR AROME systems includes $i$ ) selection of the stations and processing centers, ii) thinning, iii) bias-correction and $i v$ ) selection of the observations in the assimilation timewindow.

\subsubsection{Station-center selection, spatial and temporal thinning}

As explained before, one GPS station can be processed by several data processing centers and thus several ZTD values can be available for a given station and time. For the assimilation, we select only one solution per station by applying the procedure detailed in Poli et al. (2007). We modify it slightly to be coherent with the higher resolution of the data assimilation used in AROME. The selection is based on 15day time-series of the first-guess departure. The first-guess departure is defined as the difference between the observed ZTD and the model equivalent ZTD MODEL $_{\text {computed from }}$ the 3-h AROME forecast. The 15-day selection period lasts from 15 to 30 October 2007 being dissociated from the both assimilation periods considered in this study, but still representative of the fall season. The first step of the selection consists in conserving only station-center pairs with first-guess departure having Gaussian distribution. The KolmogorovSmirnov test is applied for that on the first-guess departure time-series of each station-center pair with a $95 \%$ confidence interval. Station-center pairs with a high coverage period are also preferred. The time coverage period must thus be higher than $40 \%$ of availability to have an homogeneous data set and to avoid sub-optimal solutions. Indeed, long data gap period favoured unaccuracy in the data set resolution. If still several centers are selectionned for a same station, the processing center for which the standard deviation of the first-guess departure is the smallest is retained. Stations where the altitude difference between station height and model ground surface exceeds $500 \mathrm{~m}$ are also removed to avoid representativeness errors. GPS observations are also horizontally thinned to a minimum distance of $10 \mathrm{~km}$ between stations. Finally we retain 282 stations over the 331 possible stations in the AROME model domain (see Fig. 1) among which 28 stations over 32 in the regional Geotrop GPS network are conserved. It is worth to mention that when a station has been both post-processsed and NRT processed by an E-GVAP center, the post-processed solution is in majority retained by 
(a)

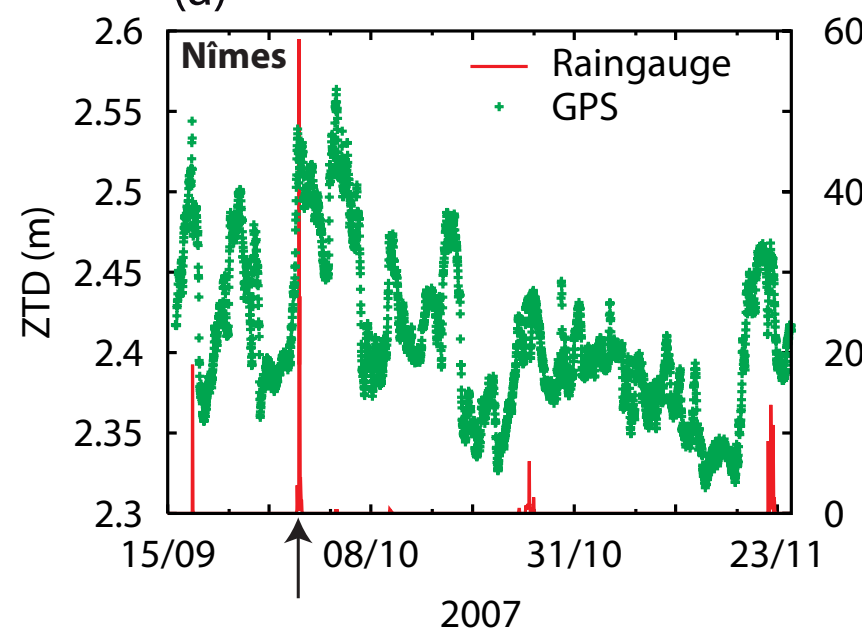

(b)

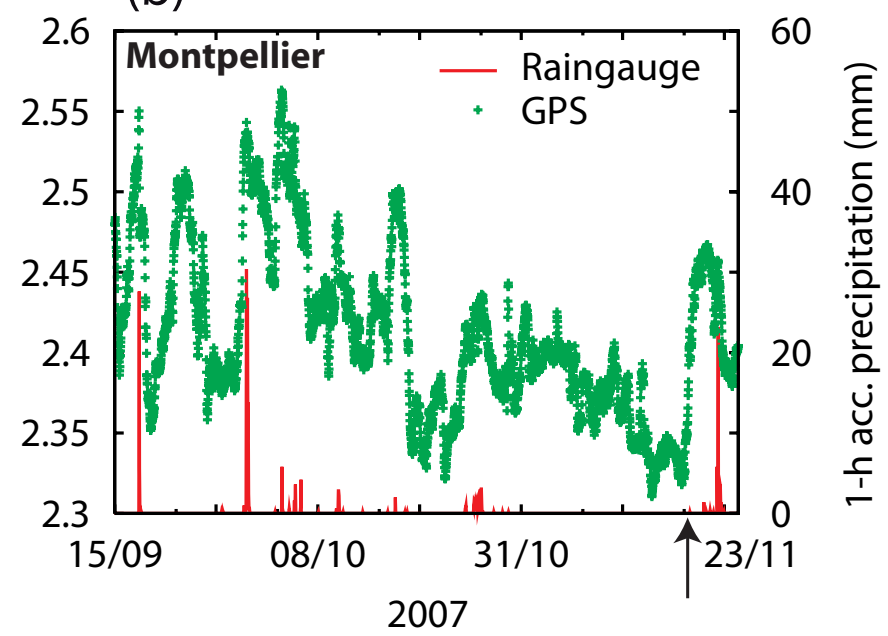

Fig. 3. Time-series evolution of ZTD (mm) and $1 \mathrm{~h}$ accumulated rainfall (mm) from 15 September 2007 to 25 November 2007 for the Nîmes (a) and Montpellier (b) GPS and rain-gauge stations. Arrows point out September and November cases.

the station-center selection. The station-center selection is thus able to select the more accurate solution of the Geotrop post-processing. Then, among the observations for a stationcenter pair within the $\pm 1 \mathrm{~h} 30$ time window of the assimilation, only the observation the closest to the analysis time is kept.

\subsubsection{Bias correction and observation error}

As variational data assimilation assumes unbiased errors, a bias-correction is applied to each observation prior the assimilation. The bias has been estimated for each station-center pair based on the 15-day mean of first-guess departure along the selection period. When the average is calculated using respectively 5 and 10 days instead of 15 days, the bias changes in average of only $1 \mathrm{~mm}$, i.e. generally less than $10 \%$ of the bias value. The sensitivity to the selected period has been also examined by choosing an other 15 -day period during fall 2007. The bias variation is only of $2 \mathrm{~mm}$ in average. One can notice that this technique is essentially statistical and does not solve the cause of model bias or other systematical model errors.

Variationnal data assimilation schemes require also estimates of the observation errors, which participate with the background errors to determine the weight of the observations relative to produce the model analysis. Observation errors include both measurement and representativeness errors. In data assimilation, these observation errors are often estimated as the standard deviation of the first-guess departure. Observation errors have been thus also estimated here as the standard deviation of the first-guess departure for each station-center pairs of the 15 -day selection period. The average value of the observation errors is $13.7 \mathrm{~mm}$, i.e. of the same order than values used in previous studies (Vedel et al., 2004; Yan et al., 2009).

\section{Case selection and experiment design}

\subsection{Study cases description}

During autumn, frequent high precipitating events followed by flash-flood affect western Mediterranean regions. The high precipitation totals are due to quasi-stationary Mesoscale Convective Systems (MCS) or to slow-moving frontal systems over the region (Rivrain, 1998; Delrieu et al., 2005; Nuissier et al., 2008). Several factors conduct to such precipitation. First, lower layers of the atmosphere extract energy and moisture from the Mediterranean Sea that acts as a reservoir especially at the end of the summer. At large scale upper-level cold troughs extending from the United Kingdom to the Iberia Peninsula generate a Southerly flow that transports the warm and moist air masses from the Mediterranean Sea toward the coast. An additional factor is due to elevated topography of the surrounding Mediterranean coast with the Alps, Pyrenees and Massif Central mountains that triggers or enhances the deep convection. The two main heavy precipitation events (29-30 September 2007, 19-22 November 2007) that occurred during fall 2007 over Southeastern France have been selected here for assessing the impact of GPS ZTD data assimilation on the AROME forecast. As shown in Fig. 3, the high precipitation rates are accompanied by increase of ZTD. Note that all increases of ZTD do not necessary lead to precipitation. One reason for that is that high ZTD means high moisture content which can be however still far from the saturation level. 
(a)

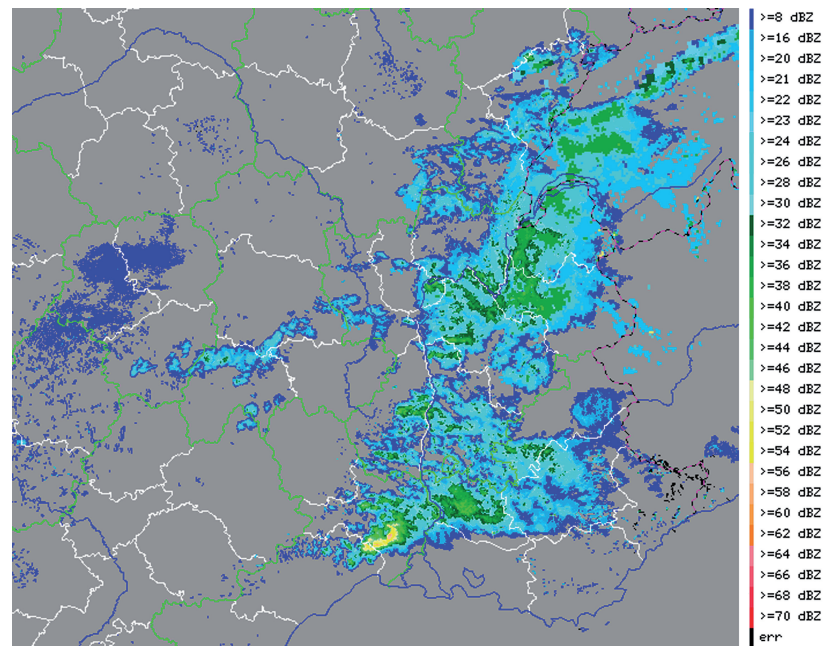

(b)

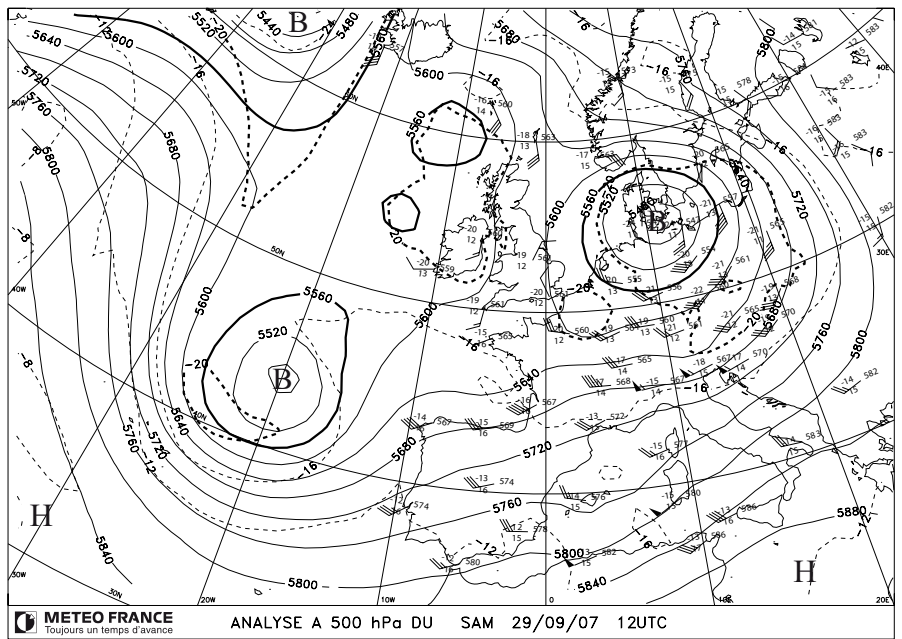

Fig. 4. (a) Radar reflectivities on 29 September 2007 at 22:00 UTC, (b) $500 \mathrm{hPa}$ geopotential heights (solid line) and temperature (dashed lines) valid at 12:00 UTC on 29 September 2007.

\subsubsection{Case study - 29-30 September 2007}

The 29 and 30 September convective rainfall hits the Gard and Herault regions (see Fig. 1 for location). Storms were locally intense with accumulated rainfall reaching 30 to $50 \mathrm{~mm}$ per hour. The daily accumulated rainfall reached $220 \mathrm{~mm}$. The first rainfall occurred around 16:00 UTC, 29 September. Then, the precipitation organized in a quasi-stationary MCS, reaching its maximum intensity around 22:00-23:00 UTC (Fig. 4a). It dissipated after 01:00 UTC.

The meteorological synoptic situation shows a rapid upper-level southwesterly flow in altitude (see Fig. 4b). The deep convection formed within the warm air ahead of a not-well marked surface front over western France. Lowlevel winds over Southeastern France are weak and mainly Southerly. The 12:00 UTC, 29 September 2007 sounding at Nîmes (not shown) shows that prior the convection triggering, the atmosphere was weakly unstable $\left(\mathrm{CAPE}=85 \mathrm{~J} \mathrm{~kg}^{-1}\right)$ and almost saturated between 900 and $750 \mathrm{hPa}$.

\subsubsection{Case study - 19-23 November 2007}

The synoptic forcing is more important in this second case. At upper levels, a pressure low center over the British Isles, 19 November 2007, generated a rapid Southwesterly flow over the Southeastern France that lasted from 19 to 23 November 2007 (Fig. 5). Associated with this upper-level low, a surface front extended from United Kingdom to Iberia peninsula on 19 November progressed slowly eastward during four days. Convection formed in the warm air ahead of the surface front the first days and then embedded within the frontal precipitation the following days. Orographic precipitation formed during the afternoon of 19 November over the

Southeastern flank of the Massif Central. Strong low-level southerly winds with wind gusts up to $90-110 \mathrm{~km} \mathrm{~h}^{-1}$ were feeding the precipitating system in moist air. The maximum of daily rainfall reaches $130 \mathrm{~mm}$. On 20 November, convection formed again ahead of the surface front during the evening, but is more widespread. The maximum of daily precipitation reaches $150 \mathrm{~mm}$. Then during the two following days, the slow-moving frontal system with embedded convection affected all the region. Daily precipitation of the 21 and 22 November reach $180 \mathrm{~mm}$ and $150 \mathrm{~mm}$, respectively. Whereas the heaviest precipitation ( $>50 \mathrm{~mm}$ in $24 \mathrm{~h}$ ) affected mostly the Southeastern Massif Central during the 21 November day, a larger area at the East of the Massif Central is concerned by the heaviest precipitation the following day.

\subsection{Experiment setup}

For each studied case, 15-day long data assimilation cycles were carried out, starting about 15 days prior the rainfall events. The first assimilation cycle is thus conducted between 15 to 30 September 2007 and the second one between 3 to 22 November 2007. For each period, two parallel experiments with and without assimilation of GPS ZTD data are performed. The control experiment (CTRL) assimilates the following operational data: land surface stations and ships, aircraft, drifting buoys, radiosondes and profilers data and also satellite sounding data (infrared and microwave radiances from the Advanced Tiros Operational Vertical Sounder - ATOVS - and the Spinning Enhanced Visible and Infrared Imager - SEVIRI on-board METEOSAT satellite, horizontal winds from atmospheric motion vectors (AMVs) and the 
(a)

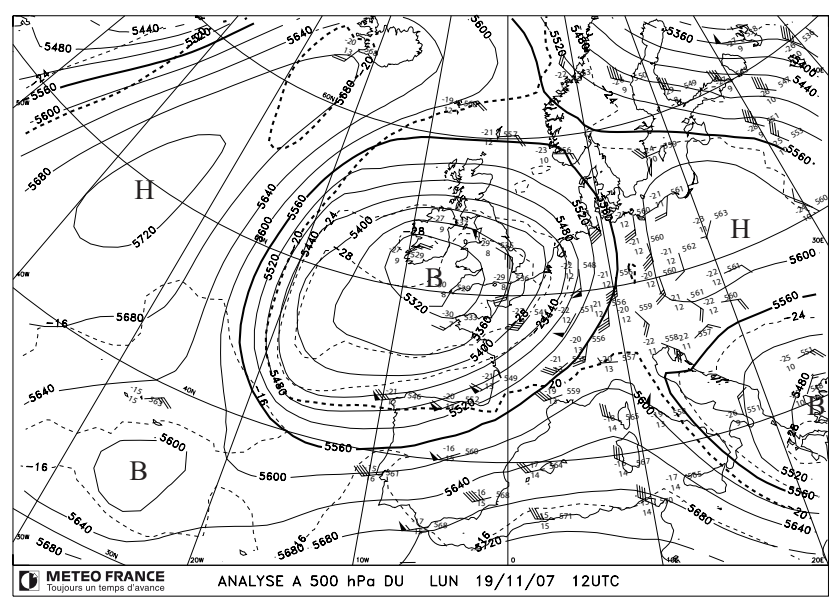

(b)

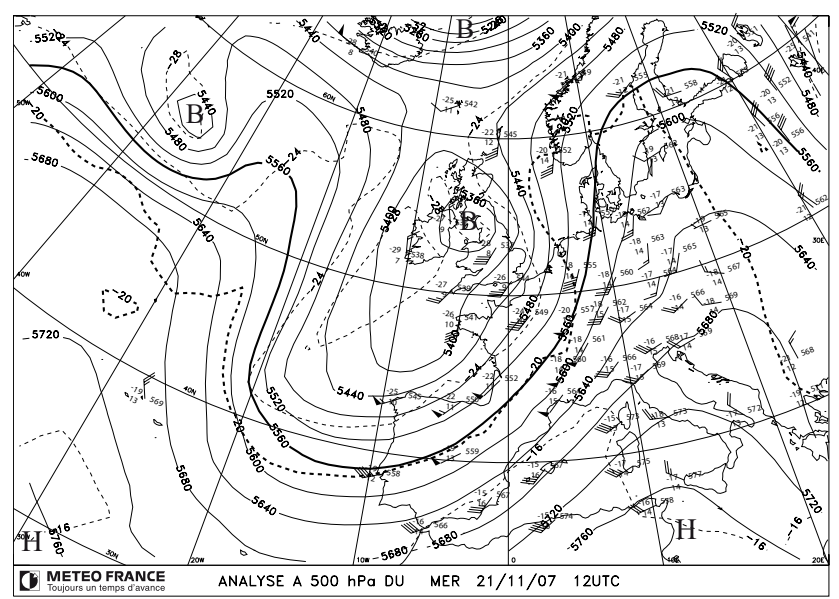

Fig. 5. Maps of $500 \mathrm{hPa}$ geopotential heights (solid line) and temperature (dashed lines) valid at 12:00 UTC on (a) 19 November 2007, (b) 21 November 2007.

(a)

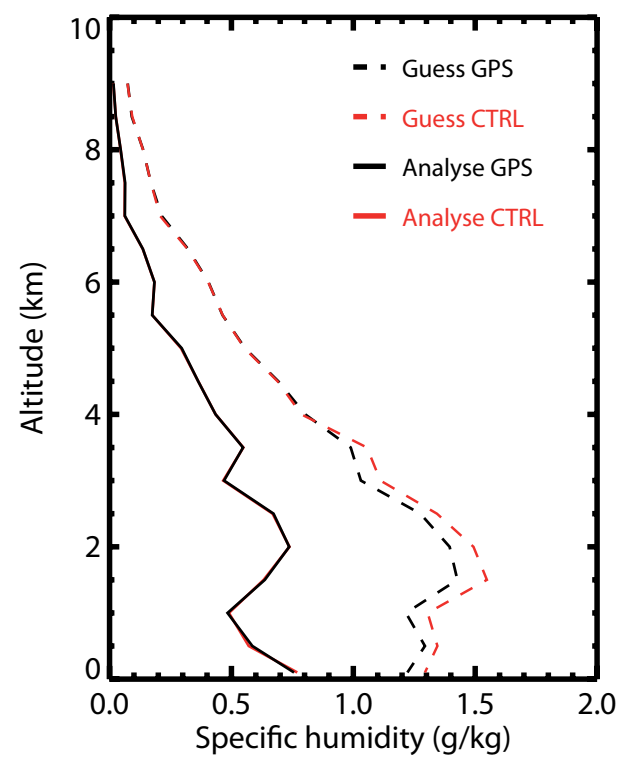

(b)

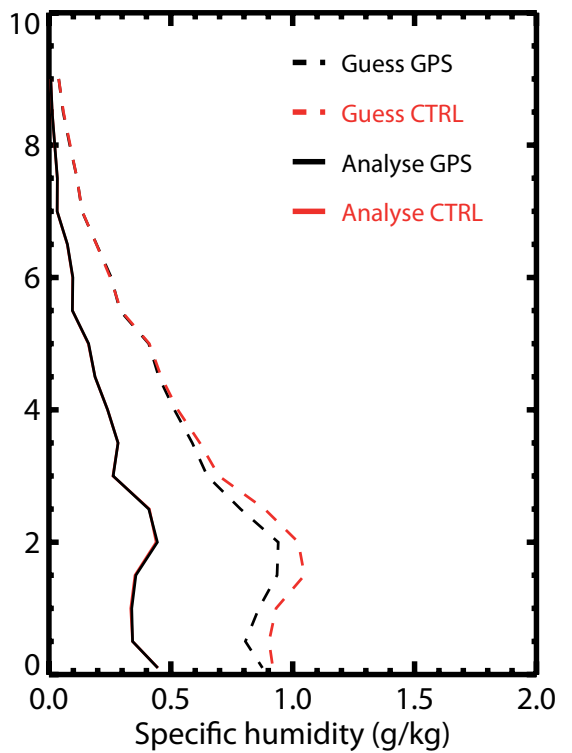

Fig. 6. Root Mean Square ( $\mathrm{g} \mathrm{kg}^{-1}$ ) of the specific humidity in function of the height for analysis and 3-h AROME forecast (guess) against observations from soundings (TEMP): (a) for the 15-day September 2007 assimilation cycles; (b) for the 15-day November 2007 assimilation cycles.

QuickScat scatterometers). GPS data are not assimilated in this experiment. The second experiment assimilates the same observations as CTRL, plus the GPS ZTD observations for the sites shown in Fig. 1. Then, for each heavy precipitation events, $30 \mathrm{~h}$ to $36 \mathrm{~h}$ AROME forecasts are carried out starting from the two sets of analyses. For the 29-30 September 2007 case, the AROME model has been run starting from analyses valid at 00:00, 06:00 and 12:00 UTC, 29 September
2007. For the 19-23 November 2007 case, only the 00:00 and 12:00 UTC analyses have been used as initial conditions to the AROME runs considering the longer event. Sixteen $36 \mathrm{~h}$-long AROME runs have been performed, covering the all precipitating period from 00:00 UTC, 19 November to 00:00 UTC, 24 November. We called hereafter these experiments $E X P H H \_M M D D$, with $E X P$ being either CTRL or GPS for the type of analyses, $H H \perp M M D D$ the hour, month 
(a)

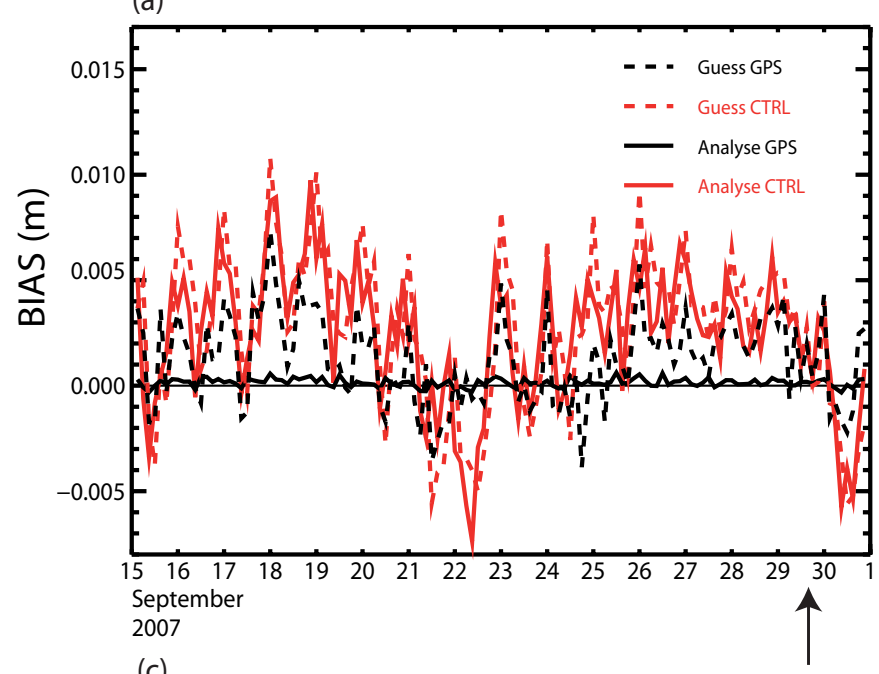

(c)

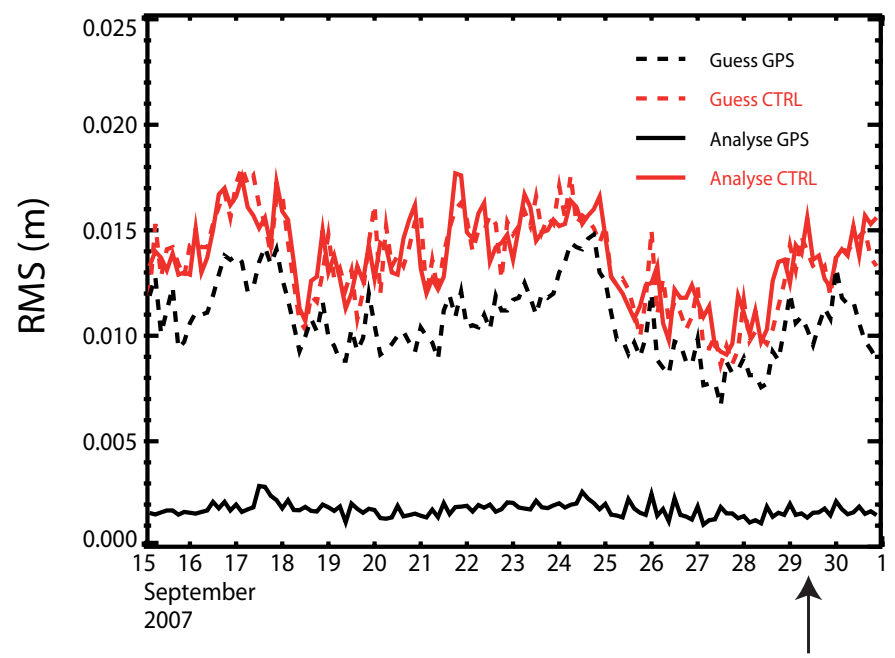

(b)

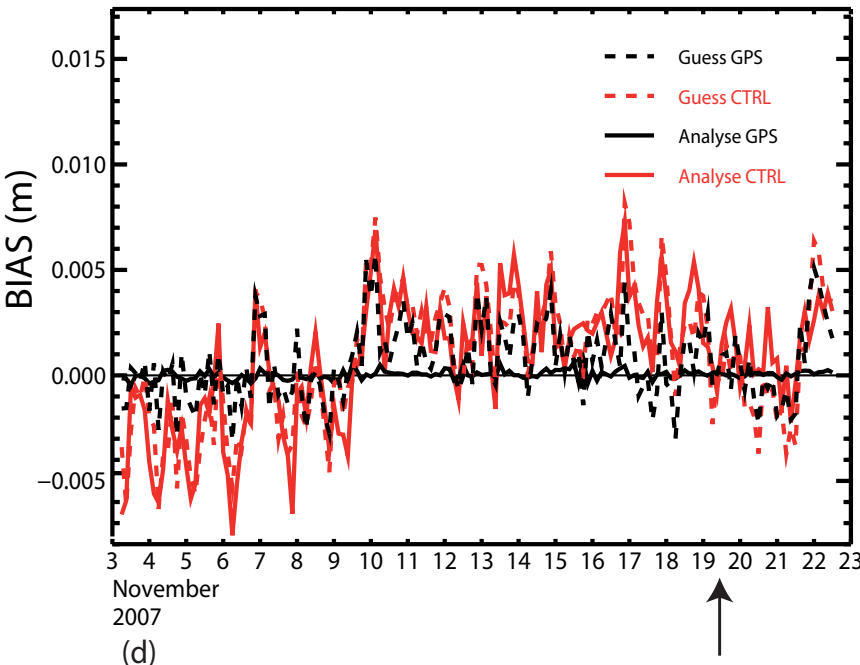

(d)

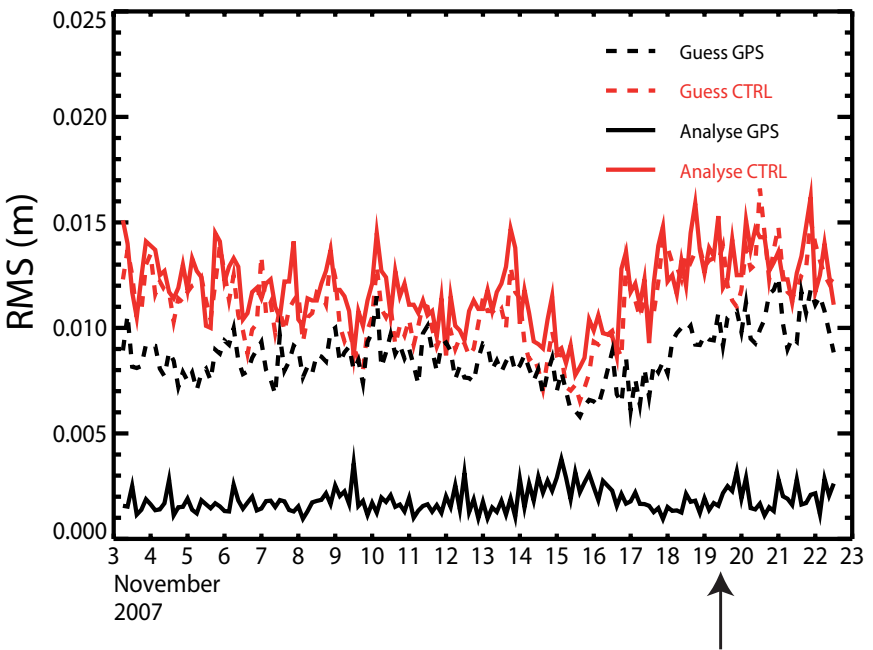

Fig. 7. Time series of (a) Average (m) of the difference ZTD OBS minus ZTDMODEL for the 15-day September 2007 assimilation cycles; (b) as panel (a) but for the 15-day November 2007 assimilation cycles; (c) Root mean square (RMS, in m) error of the difference ZTD OBS minus ZTD MODEL for the 15-day September 2007 assimilation cycles, (d) as panel (c) but for the 15-day November 2007 assimilation cycles. Arrows point out the September and November cases.

and day of the analyses used as initial conditions to the AROME run.

\section{Results}

\subsection{Impact on the 15-day assimilation cycles}

For each of the 15-day assimilation parallel cycles, the analyses and the first-guess (i.e. 3-h AROME forecast) have been verified against the assimilated observations. No significant differences between the two parallel cycles have been found for the analyses. For the guess, when differences are visible, then the guess issued from the GPS cycles are in overall better. The largest differences are found for the 3-h specific humidity forecast. Scores displayed in Fig. 6 have been computed for the 30 sounding stations included in the AROME domain. So that, for the 15 day periods, more than 19000 data coming from more than 900 soundings are taken into account for computing these scores. RMS is reduced by about $10 \%$ below $4 \mathrm{~km}$ for the 3 -h AROME forecast compared to the radiosounding specific humidity observations. Figure 7 shows the bias and the Root Mean Square error computed from all the GPS ZTD selected observations ( ZTD $\left._{\mathrm{OBS}}\right)$ along all the CTRL and GPS assimilation cycles. First of all, from Fig. 7, it can be seen that the bias fluctuates around zero for all the curves. This result confirms that data have been well unbiased during the preprocessing bias correction step. When GPS data are assimilated (i.e. GPS cycles), the 

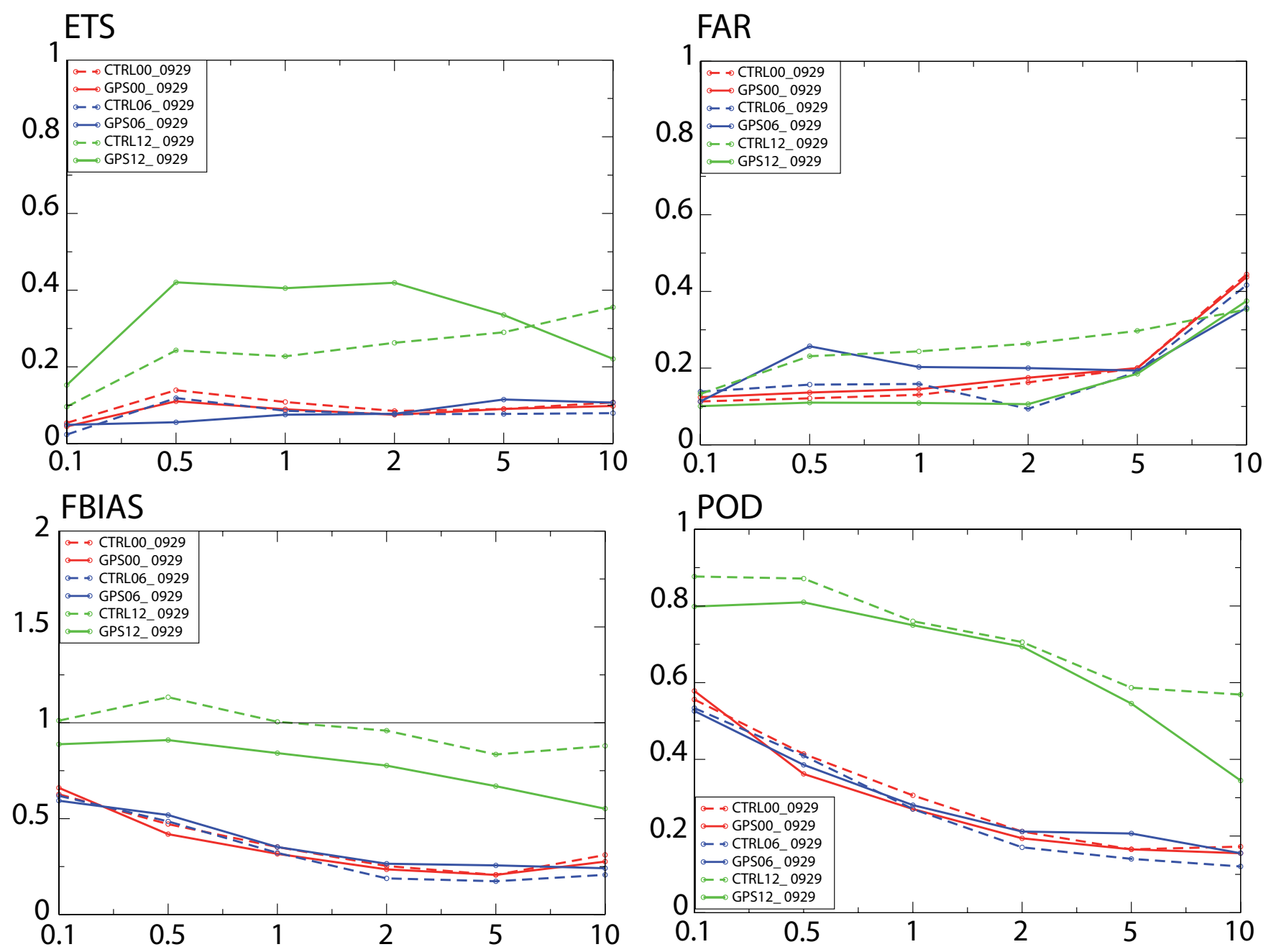

Fig. 8. Scores against rain-gauges observations for the 24-h accumulated precipitation from 12:00 UTC to 12:00 UTC, 29 September 2007 from the AROME CTRL (dashed lines) and GPS (solid lines) runs: (a) Equitable Threat Scores (ETS); (b) False Alarm Rate (FAR); (c) Frequency Bias (FBIAS) and (d) Probability Of Detection (POD) are displayed for the $0.1 \mathrm{~mm}, 0.5 \mathrm{~mm}, 1 \mathrm{~mm}, 5 \mathrm{~mm}$ and $10 \mathrm{~mm}$ thresholds. The scores have been computed over the Area 2 domain shown in Fig. 1.

mean differences between ZTD ${ }_{\mathrm{OBS}}$ and $\mathrm{ZTD}_{\mathrm{MODEL}}$ computed from the analyses are really close to zero for the two studied periods. This indicates that the assimilation of GPS data works well in drawing the analysis toward the GPS observations. The bias is significantly more important in the CTRL experiment. This demonstrates that GPS data bring an information not present in the other assimilated data. Root Mean Square errors, about 2-3 mm for the GPS analyses, are also significantly weaker than the RMS values for the CTRL analyses (about 10-15 mm). The impact of assimilating GPS data on the 3-h AROME forecast (first guess) is still significant, more specifically for the RMS. Indeed, the RMS values for the first-guess departures of the GPS assimilation cycles are weaker than those of the CTRL assimilation cycles and even weaker than those from the CTRL analyses. As a gen- eral remark, results for the two studied periods show a larger amplitude in the ZTD average differences for the September period certainly because of a higher moisture content at this time of year (Fig. 3).

\subsection{Impact on the forecast of the 29-30 September case}

The 24-h accumulated precipitation forecasts are verified against rain-gauge observations covering the rainy period, i.e. from 12:00 UTC, 29 September to 12:00 UTC, 30 September 2007. The six AROME runs, starting from the GPS and CTRL analyses at 00:00 UTC, 06:00 UTC and 12:00 UTC, respectively, are examined. Figure 8 shows the Equitable Threat Score (ETS), the Frequency Bias (FBIAS), the False Alarm Ratio (FAR) and the Probability Of Detection (POD) for precipitation thresholds ranging from the 
(a)

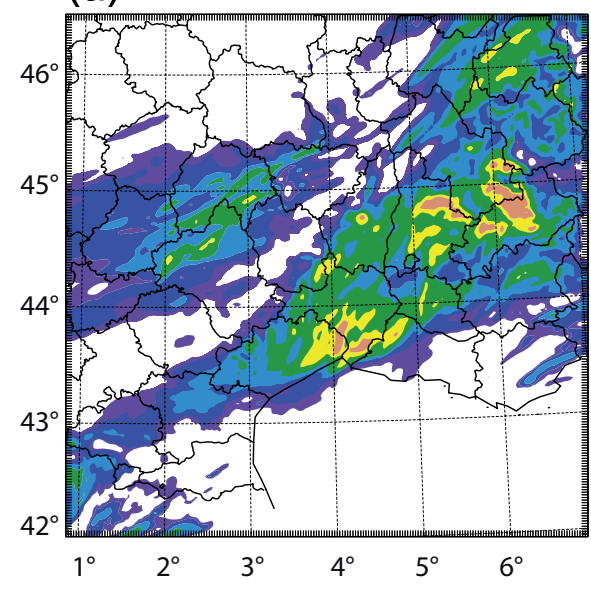

(b)

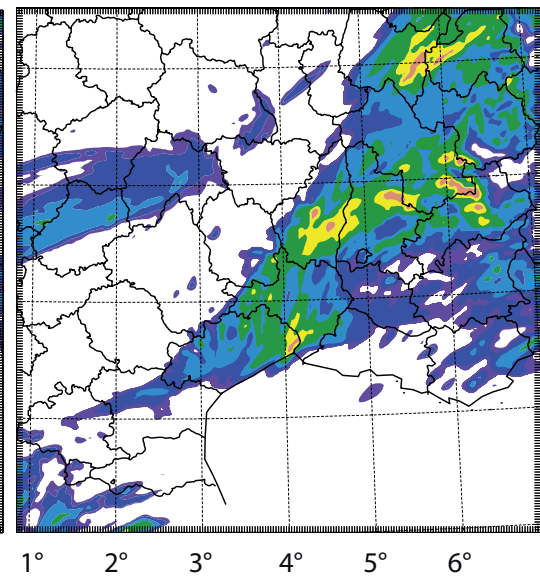

(c)

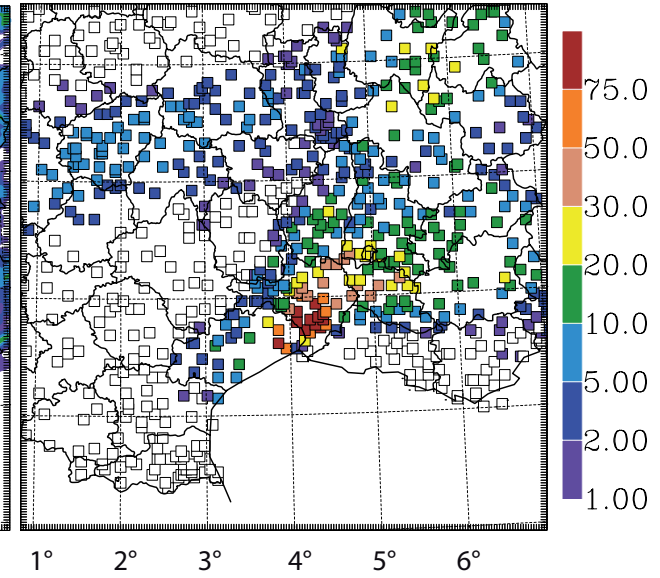

Fig. 9. 24-h accumulated precipitation from 12:00 UTC to 12:00 UTC, 29 September 2007 over the Area 2 domain for (a) CTRL12_0929 AROME run; (b) GPS12_0929 AROME run; (c) rain-gauge observations.

rain/no rain threshold (i.e. $0.1 \mathrm{~mm}$ ) to $10 \mathrm{~mm}$. Figure 8 reveals notable discrepancies between the AROME forecasts starting from the 12:00 UTC analyses and those computed from runs starting from the 00:00 and 06:00 UTC analyses. ETS values are close to zero whatever the thresholds for these later experiments. FBIAS, FAR and POD indicate better values for the rain/no rain threshold but still poor results for the other thresholds. We remind that perfect score values for FBIAS, ETS, FAR and POD are 1, 1, 0 and 1, respectively. Using an analysis which has benefited from GPS ZTD assimilation does not improve the results. For the runs starting from the 12:00 UTC analyses (GPS12_0929 and CTRL12_0929), the scores indicate better forecast of the quantitative precipitation and the differences between the GPS12_0929 and CTRL12_0929 are also larger. The GPS12_0929 run has better ETS, FAR and FBIAS scores for thresholds lower than $5 \mathrm{~mm}$, whereas for the $10 \mathrm{~mm}$ threshold the CTRL12_0929 performs better. Indeed, the CTRL12_0929 forecast overestimates the weak precipitation and the extent of the precipitation area. Figure 9 shows that the precipitation is reduced in GPS12_0929 over the western part of the domain in agreement with the rain-gauge observations. On the opposite, the highest rainfall totals over the Gard region are weaker in GPS12_0929, explaining the worse scores for the $10 \mathrm{~mm}$ threshold.

Differences between the GPS12_0929 and CTRL12_0929 precipitation forecast can be partly explained by differences in the humidity analyses. Figure 10 shows the Integrated Water Vapour (IWV) from the 12:00 UTC GPS analysis and the differences in IWV between the GPS and the CTRL analyses. The IWV value is reduced by $15-20 \%$ over the Western part of the domain for the GPS analysis. The low-level Easterly flow that feeds the precipitating system in this region supplies thus less precipitable water to the system. This could explain why the precipitation is reduced in the GPS12_0929 AROME run compared to the CTRL12_0929 one. No such direct link with the analysed IWV fields can be found however for the underestimation of the heaviest precipitation over the Gard region.

\subsection{Impact on the forecast of the 19-23 November case}

For the second case, the meteorological situation responsible of the 4-days successive rainfall is characterized by a slow-moving frontal system passing over South of France. In this case, the AROME forecast had a quite good accuracy according to scores computed on the precipitation forecast. A big picture of the quality of the AROME runs is provided in Fig. 11. FAR and POD have been computed gathering all the first 24-h precipitation total forecast from the 8 AROME runs of each parallel experiment. The Probability of Detection is high with a False Alarm Ratio weak whatever the threshold. Figure 12 shows that the timing of the successive rainfall events is also quite well reproduced by all the runs. The precipitation intensity is remarkably well simulated by almost all the AROME runs. The last event is also the most intense event for the AROME runs, although its intensity is underestimated. Figures 11 and 12 show that the skill of the GPS and CTRL runs is quite similar. Figures 13 and 14, showing the $24 \mathrm{~h}$ cumulated rainfall for the AROME runs and observations on 21 November and 22 November confirms that with heavy rain located at the same place in both runs. In fact, the analyses produced by the assimilation cycle using in addition the GPS ZTD observations are not so different than those produced by the control assimilation cycle. As shown by Fig. 7b, the mean differences between the observed ZTD and the ZTD computed 
(a) IWV

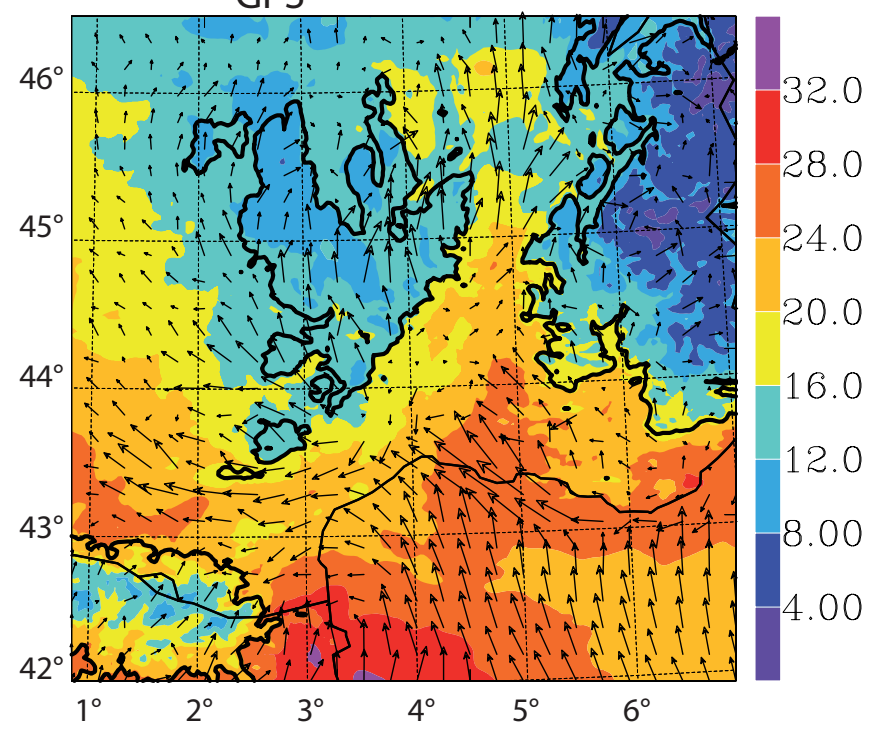

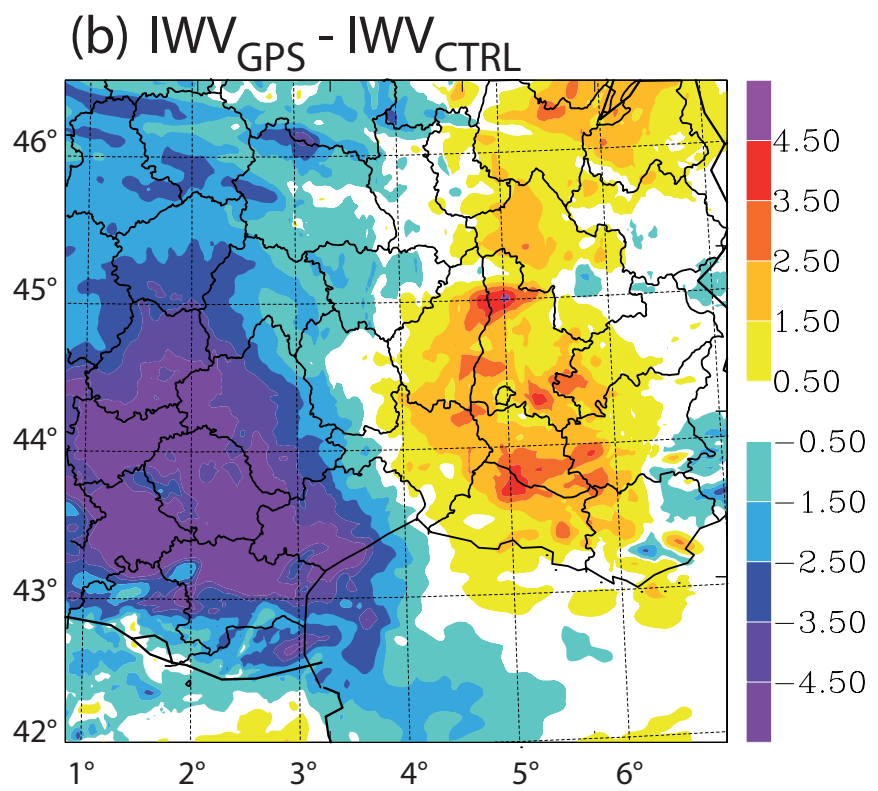

Fig. 10. Integrated water vapor $\left(\mathrm{kg} \mathrm{m}^{-2}\right)$ of the GPS experiment on the 29 September 2007 for the 12UTC analysis on (a) wind direction at $32 \mathrm{~m}$ is also described. Relief at $500 \mathrm{~m}$ is emphasized by a thick black line, (b) difference of IWV between GPS and CTRL experiment at the same time. Administrative regions are delimited by a thin black line.

(a) FAR

1

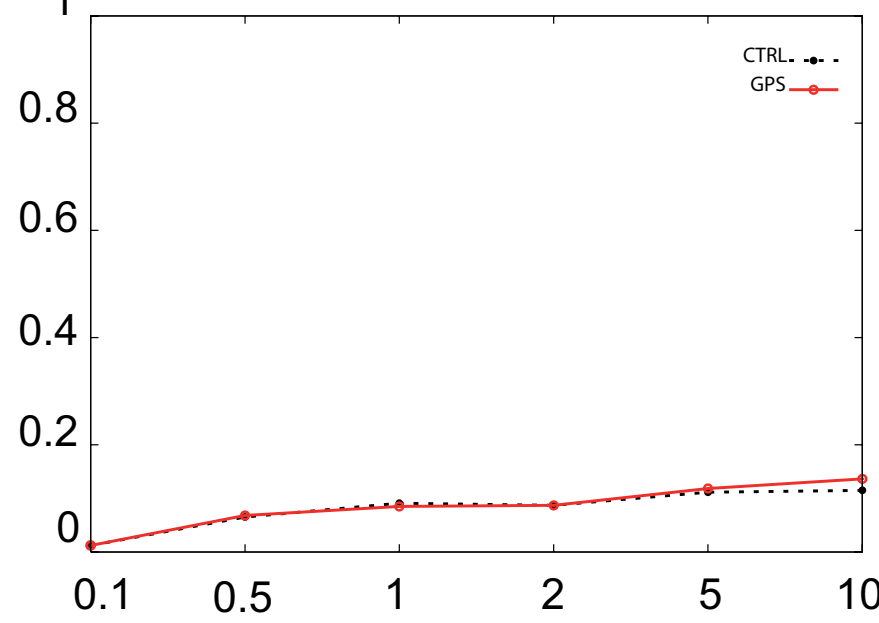

(b) POD

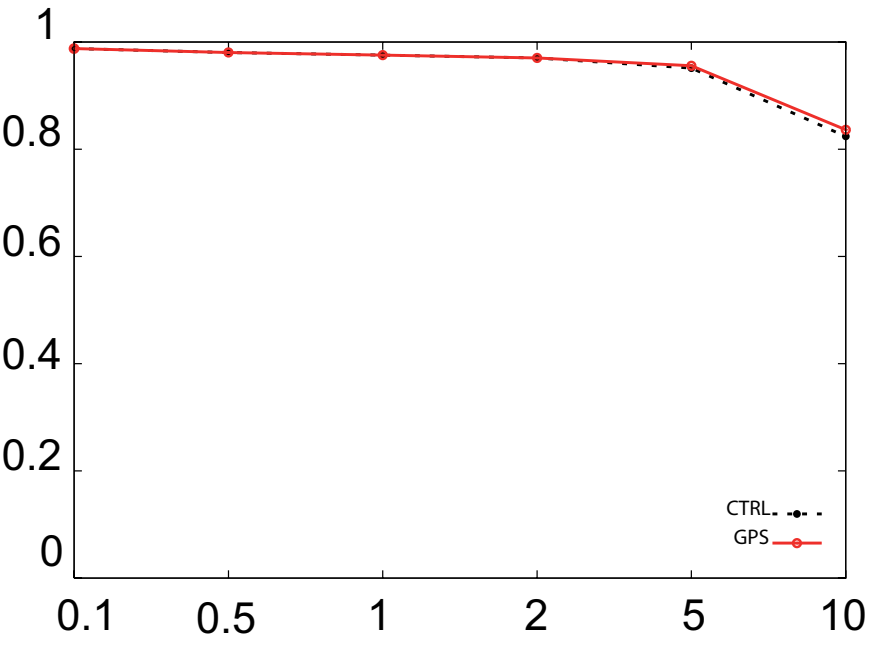

Fig. 11. Scores against rain-gauge observations for the 24-h accumulated precipitation from all the 8 AROME runs performed from 19 to 22 November 2007: (a) False Alarm Rate (FAR); (b) Probability Of Detection (POD). They are displayed for the $0.1 \mathrm{~mm}, 0.5 \mathrm{~mm}, 1 \mathrm{~mm}, 5 \mathrm{~mm}$ and $10 \mathrm{~mm}$ thresholds and have been computed over the Area 2 domain shown in Fig. 1.

from the CTRL analyses are small from 19 to 21 November. Differences are more important for the 22 November and may explain the larger discrepancies found between the GPS00_1122 and CTRL00_1122 AROME runs and also between the GPS12_1122 and CTRL12_1122 AROME runs during the first 6 to $12 \mathrm{~h}$ of simulation (Fig. 12). In both cases, the GPS AROME runs are closer to the observations.
From the results obtained on this case, we can thus infer that the atmosphere state is quite well described in the initial conditions of the CTRL runs leading to high quality precipitation forecast. When the state of the atmosphere is well determined, it is more difficult to improve the forecast accuracy by adding more observations as found for example by Gutman et al. (2004). It applies to the case of 19-23 November 
(a)

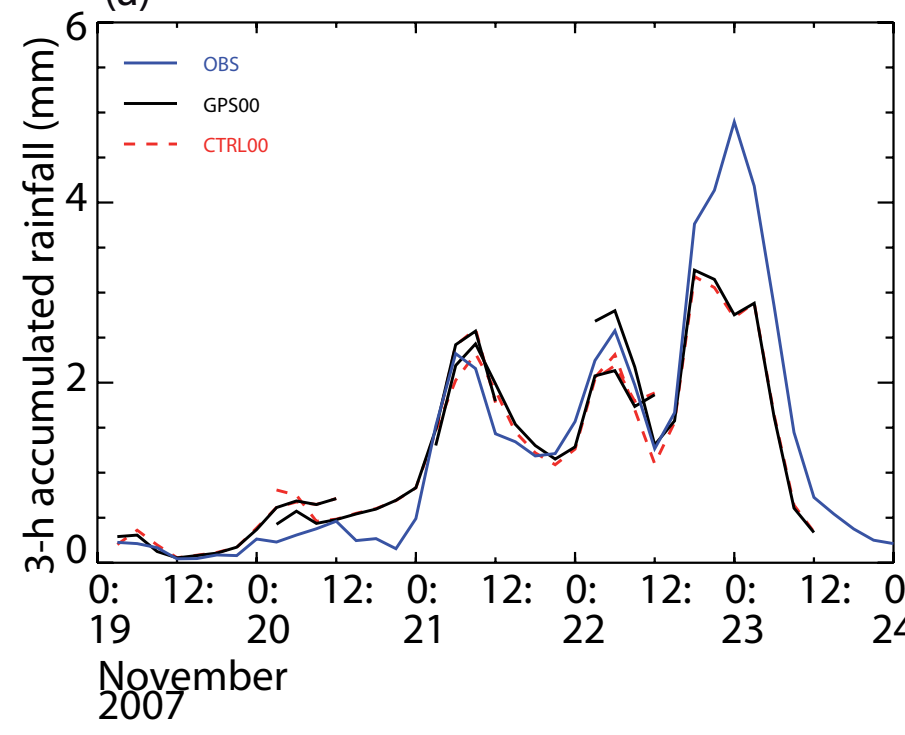

(b)

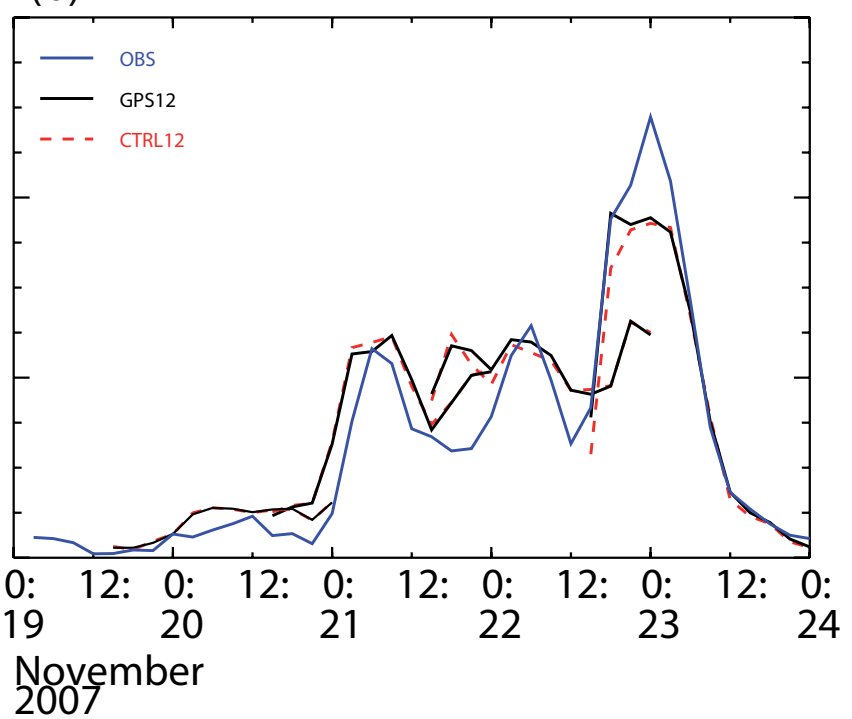

Fig. 12. Time-series of 3-h accumulated precipitation $(\mathrm{mm})$ averaged over Area 2 shown in Fig. 1: (a) for the GPSO0_MMDD and CTRL00_MMDD AROME runs with $\_M M D D=1119,1120,1121,1122$; (b) for the GPS12_MMDD and CTRL12_MMDD AROME runs with $M M D D=1119,1120,1121,1122$. The 3-h accumulated precipitation from rain-gauge observations averaged over the same domain are also drawn with blue lines.

2008, with quite good accuracy for the AROME forecasts and differences between GPS and CTRL AROME runs not significant for most of the runs.

\section{Discussion and conclusions}

The data assimilation experiments described in this study were one of the first attempt using the AROME highresolution NWP system to assimilate mesonet GPS ZTD observations. Data from more than 280 stations over the AROME domain have been assimilated during 15-day long assimilation cycles prior each of the two studied events. The results of these assimilation cycles show that the assimilation of GPS ZTD with the AROME system performs well in producing analyses closer to the ZTD observations in average. This demonstrates one more time that GPS data bring a relevant information not provided by other observation systems.

The impact of assimilating GPS ZTD data on precipitation forecast has been examined for the two main heavy rainfall events occurred during fall 2007 over Southeastern France. These two events are quite different, but also representative of the two kinds of heavy rainfall encountered over this region. For the first one, the large rainfall totals are mainly attributable to a quasi-stationary mesoscale convective system. Larger synoptic forcing prevailed for the second case, with convective precipitation ahead and embedded in a slowmoving frontal system. The impact of assimilating GPS data is quite different for the two cases due to the different types of meteorological situations and the quality of the AROME control analyses and forecasts. For the first case, only the AROME runs starting from the 12:00 UTC analyses, a few hours prior the triggering of the convective system, are able to simulate the convective precipitation. The assimilation of GPS ZTD observations in the 12:00 UTC analysis by drying part of the region allows to reduce in the forecast the precipitation extent and the weak precipitation compared to the control run. However scores for the heaviest precipitation are slightly deteriorates.

The accuracy of the AROME precipitation forecast for the second case is much better. The AROME analyses from the control assimilation cycle provide a sufficient description of the atmosphere state allowing to simulate quite well the precipitating systems. The assimilation of GPS ZTD data can not thus add significant corrections of the atmosphere state. The AROME forecast starting from the GPS analyses are thus close to the control ones. The largest differences between the two forecasts have been found for the latest day (22 November 2007). Assimilation of GPS ZTD allows to improve the first 6 to $12 \mathrm{~h}$ of the precipitation forecast for that day.

Even though the above conclusions cannot be definitive due to the limited number of cases studied, this study shows that the value of the assimilation of a specific observing system depends on the predictability of the events. An overall neutral impact is expected when predictability is high whereas a more likely significant impact would occur with weak predictability situations. At mesoscale and for 
(a)

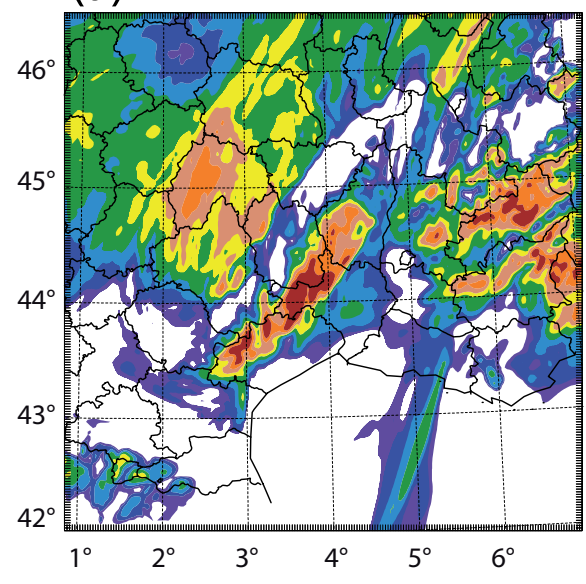

(b)

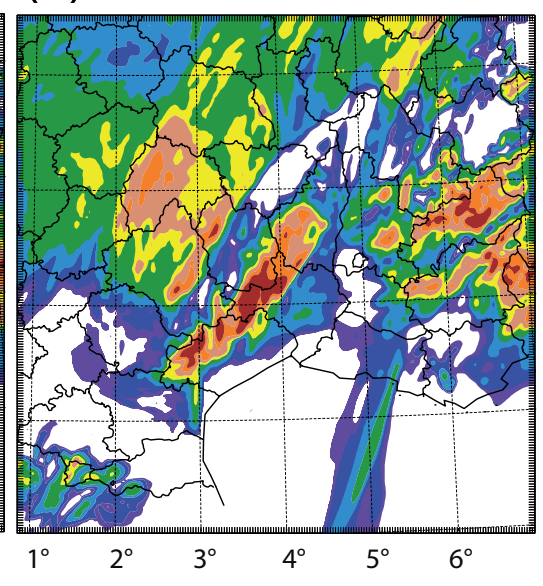

(c)

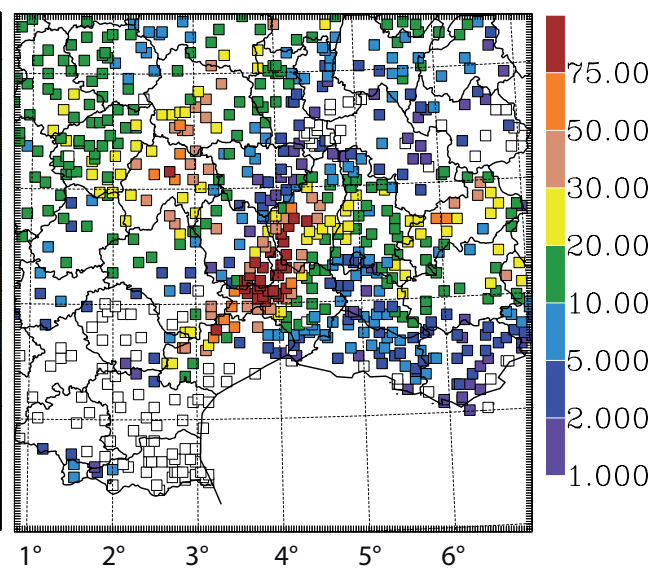

Fig. 13. 24-h accumulated precipitation from 21 November, 00:00 UTC to 22 November 2007, 00:00 UTC over the Area 2 domain for (a) CTRL00_1121 AROME run; (b) GPS00_1121 AROME run; (c) rain-gauge observations.

(a)

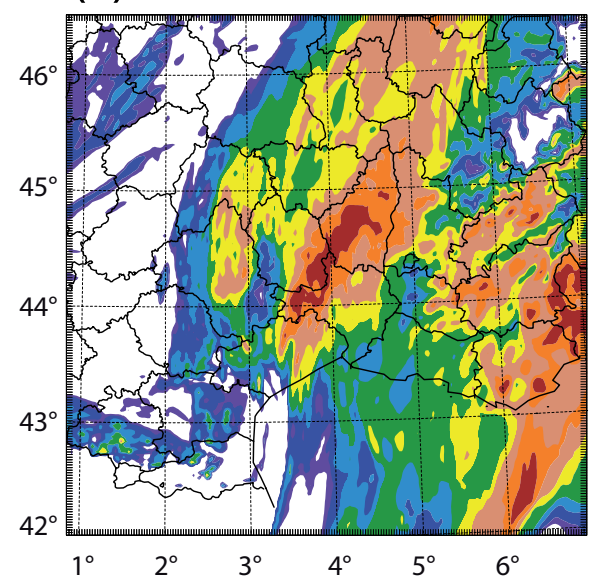

(b)

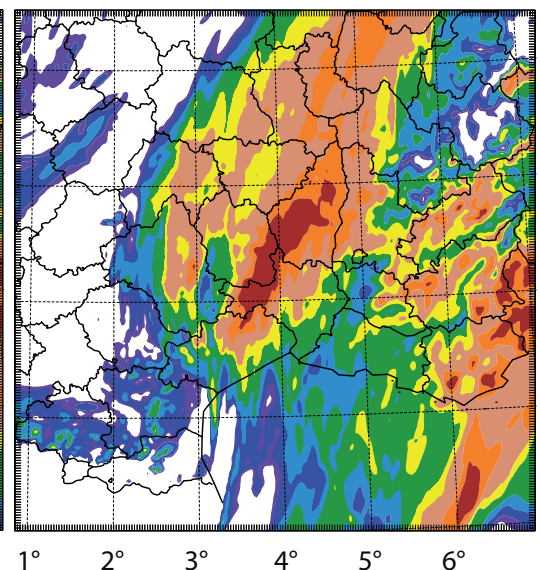

(c)

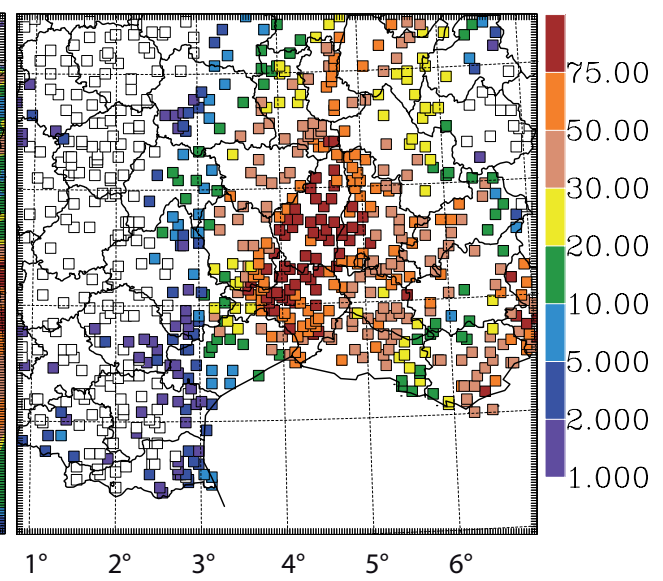

Fig. 14. 24-h accumulated precipitation from 22 November, 00:00 UTC to 23 November 2007, 00:00 UTC over the Area 2 domain for (a) CTRL00_1122 AROME run; (b) GPS00_1122 AROME run; (c) rain-gauge observations.

very-short range considered here, it cannot be denied that the configuration of the observation network is of importance also. Indeed, Southeastern France precipitating systems are fed by low-level moist plumes over the Mediterranean Sea, which is void of GPS stations. Even though this study makes use of data from a regional GPS network over land in southeastern France in addition to those from the operational European E-GVAP network, information about moisture along the fetch of the low-level jet over the Sea are missing. A companion study (Yan et al., 2009) performed with the same AROME NWP system but for precipitating events over Northern France found more significant positive impact. More numerous upwind GPS stations assimilated in this study likely explain this stronger impact. The ongoing demonstration of the feasibility of processing ZTD from GPS receiver platforms on board ships or buoys (see Kelecy et al., 1994; Rocken et al., 2005; Fujita et al., 2008, among others) opens new horizons for the assimilation of GPS data to improve forecast of Mediterranean heavy precipitation events. They will be explored in the framework of the future HyMeX (Hydrological Cycle in the Mediterranean eXperiment) field campaign (http://www.cnrm.meteo.fr/hymex/) during which the impact of ZTD data that could be collected by GPS receiver platforms deployed in the Mediterranean Sea, either on ferries or on research vessels would be assessed. 
Acknowledgements. The authors would like to thank support from RENAG and the OHM-CV project to maintain the Geotrop GPS network. Collaboration with the RGP and the Orphéon private company allowed to receive more data within the Geotrop network. The authors would like also to thank Philippe Collard for installing and maintaining most of the receivers of the Geotrop network. Thanks go also to the two anonymous reviewers that helped to improve the manuscript.

Topical Editor F. D'Andrea thanks K. Lagouvardos and another anonymous referee for their help in evaluating this paper.

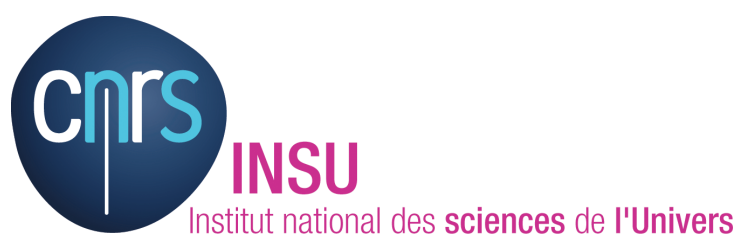

The publication of this article is financed by CNRS-INSU.

\section{References}

Anthes, R.: Regional Models of the Atmosphere in Middle Latitudes, Mon. Weather Rev., 111, 1306-1335, 1983.

Benard, P.: On the use of a wider class of linear systems for the design of constant-coefficients semi-implicit time schemes in NWP, Mon. Weather Rev., 132, 1319-1324, 2004.

Berre, L., Stefanescu, S., and Pereira, M.: The representation of the analysis effect in three error simulation techniques, Tellus Series A-Dynamic Meteorology and Oceanography, 58, 196-209, 2006.

Bevis, M., Businger, S., Herring, T., C., R., Anthes, R., and Ware, R.: GPS Meteorology : Remote Sensing of Atmospheric Water Vapor Using the Global Positioning System, J. Geophys. Res., 97, 15787-15801, 1992.

Bock, O., Keil, C., Richard, E., Flamant, C., and Bouin, M.: Validation of precipitable water from ECMWF model analyses with GPS and radiosonde data during the MAP SOP, Q. J. Roy. Meteorol. Soc., 131, 3013-3036, 2005.

Bouttier, F.: Arome, avenir de la prévision régionale, La Météorologie, 58, 12-20, 2007.

Brenot, H., Ducrocq, V., Walpersdorf, A., Champollion, C., and Caumont, O.: GPS Zenith Delay Sensitivity Evaluated from High-Resolution NWP simulations of the $8-9^{\text {th }}$ September 2002 Flash-Flood over Southeastern France, J. Geophys. Res., 111, D15105, doi:10.1029/2004JD005726, 2006.

Bubnova, R., Hello, G. P. B., and Geleyn, J.-F.: Integration of the fully elastic equations cast in the hydrostatic pressure terrainfollowing coordinate in the framework of the Arpge/Aladin NWP system., Mon. Weather Rev., 123, 515-535, 1995.

Caniaux, G., Redelsperger, J., and Lafore, J.: A Numerical Study of the Stratiform Region of a Fast-Moving Squall Line .1. General Description and Water and Heat Budgets, J. Atmos. Sci., 51, 2046-2074, 1994.

Champollion, C., Masson, F., Van Baelen, J., Walpersdorf, A., Chery, J., and Doerflinger, E.: GPS monitoring of the tropospheric water vapor distribution and variation during the 9 September 2002 torrential precipitation episode in the
Cevennes (Southern France), J. Geophys. Res., 109, D24102, doi:10.1029/2004JD004897, 2004.

Courtier, P., Thepaut, J., and Hollingsworth, A.: A Strategy for Operational Implementation of 4D-VAR, Using an Incremental Approach, Q. J. Roy. Meteorol. Soc., 120, 1367-1387, 1994.

Cuxart, J., Bougeault, P., and Redelsperger, J.: A turbulence scheme allowing for mesoscale and large-eddy simulations, Q. J. Roy. Meteorol. Soc., 126, 1-30, 2000.

Delrieu, G., Ducrocq, V., Gaume, E., Nicol, J., Payrastre, O., Yates, E., Kirstetter, P., Andrieu, H., Ayral, P., Bouvier, C., Creutin, J., Livet, M., Anquetin, S., Lang, M., Neppel, L., Obled, C., Parentdu Chatelet, J., Saulnier, G., Walpersdorf, A., and Wobrock, W.: The catastrophic flash-flood event of 8-9 September 2002 in the Gard region, France: A first case study for the Cevennes-Vivarais Mediterranean Hydrometeorological Observatory, J. Hydrometeorol., 6, 34-52, 2005.

Ducrocq, V., Ricard, D., Lafore, J., and Orain, F.: Storm-scale numerical rainfall prediction for five precipitating events over France: On the importance of the initial humidity field, Weather and Forecasting, 17, 1236-1256, 2002.

Emardson, T., Elgered, G., and Johansson, J.: Three months of continuous monitoring of atmospheric water vapor with a network of Global Positioning System receivers, J. Geophys. Res. Atmos., 103, 1807-1820, 1998.

Fischer, C., Montmerle, T., Berre, L., Auger, L., and Stefanescu, S.: An overview of the variational assimilation in the ALADIN/France numerical weather-prediction system, Q. J. Roy. Meteorol. Soc., 131, 3477-3492, doi:10.1256/qj.05.115, 2005.

Fujita, M., Kimura, F., Yoneyama, K., and Yoshizaki, M.: Verification of precipitable water vapor estimated from shipborne GPS measurements, Geophys. Res. Lett., 35, L13803, doi:10.1029/2008GL033764, 2008.

Gutman, S., Sahm, S., Benjamin, S., Schwartz, B., Holub, K., Stewart, J., and Smith, T.: Rapid retrieval and assimilation of ground based GPS precipitable water observations at the NOAA forecast systems laboratory: Impact on weather forecasts, J. Meteorol. Soc. Jpn., 82, 351-360, 2004.

Kelecy, T., Born, G., Parke, M., and Rocken, C.: Precise Mean SeaLevel Measurements Using The Global Positioning System, J. Geophys. Res.-Oceans, 99, 7951-7959, 1994.

King, R. and Bock, Y.: Documentation for the GAMIT GPS analysis software, Release 10.32. Mass. Inst. of Technol., Cambridge., 2007.

Klein Baltink, H., Van Der Marel, H., and Van Der Hoeven, A. G. A.: Integrated atmospheric water vapor estimates from a regional GPS network, J. Geophys. Res., 107, 4025, doi:10.1029/ 2000JD000094, 2002.

Kopken, C.: Validation of integrated water vapor from numerical models using ground-based GPS, SSM/I, and water vapor radiometer measurements, J. Appl. Meteor., 40, 1105-1117, 2001.

Kuo, Y., Zou, X., and Guo, Y.: Variational assimilation of precipitable water using a nonhydrostatic mesoscale adjoint model .1. Moisture retrieval and sensitivity experiments, Mon. Weather Rev., 124, 122-147, 1996.

Kuo, Y., Zou, X., and Huang, W.: The impact of Global Positioning System data on the prediction of an extratropical cyclone: an observing system simulation experiment, Dynam. Atmos. Oceans, 27, 439-470, 1998.

Lafore, J., Stein, J., Asencio, N., Bougeault, P., Ducrocq, V., Duron, 
J., Fischer, C., Hereil, P., Mascart, P., Masson, V., Pinty, J., Redelsperger, J., Richard, E., and de Arellano, J.: The Meso-NH atmospheric simulation system. Part I: adiabatic formulation and control simulations, Ann. Geophys.-Atmospheres Hydrospheres and Space Sciences, 16, 90-109, 1998.

Masson, V.: A physically-based scheme for the urban energy budget in atmospheric models, Bound.-Lay. Meteorol., 94, 357-397, 2000.

Mlawer, E., Clough, S., Brown, P., Stephen, T., Landry, J., Goldman, A., and Murcray, F.: Observed atmospheric collisioninduced absorption in near-infrared oxygen bands, J. Geophys. Res.-Atmos., 103, 3859-3863, 1998.

Montmerle, T., Rabier, F., and Fischer, C.: Relative impact of polar-orbiting and geostationary satellite radiances in the Aladin/France numerical weather prediction system, Q. J. Roy. Meteorol. Soc., 133, 655-671, 2007.

Niell, A.: Global mapping functions for the atmosphere delay at radio wavelengths, J. Geophys. Res., 101, 3227-3246, 1996.

Noilhan, J. and Mahfouf, J.: The ISBA land surface parameterisation scheme, Global and Planetary Change, 13, 145-159, 1996.

Nuissier, O., Ducrocq, V., Ricard, D., Lebeaupin, C., and Anquetin, S.: A numerical study of three catastrophic precipitating events over southern France. I: Numerical framework and synoptic ingredients, Q. J. Roy. Meteorol. Soc., 134, 111-130, 2008.

Poli, P., Moll, P., Rabier, F., Desroziers, G., Chapnik, B., Berre, L., Healy, S. B., Andersson, E., and El Guelai, F.-Z.: Forecast impact studies of zenith total delay data from European near realtime GPS stations in Météo France 4DVAR, J. Geophys. Res., 112, D06114, doi:10.1029/2006JD007430, 2007.

Rivrain, J.: Les épisodes orageux à précipitations extrêmes dans les régions Méditerrannéennes du sud de la France (Storm-floods in the Mediterranean region of southern of France), Phénomènes remarquables, vol. 4, météo-france, scem edn., 1998.

Rocken, C., Vanhove, T., Johnson, J., Solheim, F., Ware, R., Bevis, M., Chiswell, S., and Businger, S.: GPS/STORM - GPS Sensing of Atmospheric Water-Vapor for Meteorology, J. Atmos. Oceanic Technology, 12, 468-478, 1995.
Rocken, C., Johnson, J., Van Hove, T., and Iwabuchi, T.: Atmospheric water vapor and geoid measurements in the open ocean with GPS, Geophys. Res. Lett., 32, L12813, doi:10.1029/2005GL022573, 2005.

Saastamoinen, J.: Introduction to practical computation of astronomical refraction, Bull. Geod., 106, 389-397, 1972.

Smith, E. and Weintraub, S.: The constants in the equation for atmospheric index at radio frequencies, Proc. IRE, 41, 1035-1037, 1953.

Tregoning, P., Boers, R., O'Brien, D., and Hendy, M.: Accuracy of absolute precipitable water vapor estimates from GPS observations, J. Geophys. Res.-Atmos., 103, 28701-28710, 1998.

Vedel, H. and Huang, X.: Impact of ground based GPS data on numerical weather prediction, J. Meteorol. Soc. Jpn., 82, 459-472, International Workshop on GPS Meteorology, Tsukuba, JAPAN, 14-17 January 2003, 2004.

Vedel, H., Huang, X., Haase, J., Ge, M., and Calais, E.: Impact of GPS Zenith Tropospheric Delay data on precipitation forecasts in Mediterranean France and Spain, Geophys. Res. Lett., 31, L02102, doi:10.1029/2003GL017715, 2004.

Yan, X., Ducrocq, V., Poli, P., Jaubert, G., and Walpersdorf, A.: Mesoscale GPS Zenith Delay assimilation during a Mediterranean heavy precipitation event, Adv. Geosci., 17, 71-77, 2008, http://www.adv-geosci.net/17/71/2008/.

Yan, X., Ducrocq, V., Jaubert, G., Brousseau, P., Poli, P., Champollion, C., and Boniface, K.: Benefit of GPS Zenith Delay Assimilation on high-resolution Quantitative Precipitation Forecast of the COPS cases IOP9, Q. J. Roy. Meteorol. Soc., accepted, 2009.

Zhang, C., Kuo, Y., Dai, L., Chu, Y., Braun, J., Zhang, J., Li, Q., and Chen, M.: The Design and Application of Network of GroundBased GPS Water Vapor Monitoring stations to Improve Precipitation Precipitation Prediction in the Greater Beijing Metropolitan area, The International Archives of the Photogrammetry, Remote Sensing and Spatial Information Sciences, 37, 2008.

Zou, X., Kuo, Y., and Guo, Y.: Assimilation of Atmospheric Radio Refractivity using a Nonhydrostatic Adjoint Model, Mon. Weather Rev., 123, 2229-2249, 1995. 